\title{
A natural biopreservative: Antibacterial action and mechanisms of Chinese Litsea mollis Hemsl. extract against Escherichia coli DH5a and Salmonella spp.
}

\author{
XiaoTian Cai, ${ }^{1}$ Xue Wang, ${ }^{2,3}$ YiCun Chen, ${ }^{2,3}$ YangDong Wang, ${ }^{2,3}$ DaFeng Song, ${ }^{1 *}$ and Qing Gu ${ }^{1 *}$ \\ ${ }^{1}$ Key Laboratory for Food Microbial Technology of Zhejiang Province, Zhejiang Gongshang University, Hangzhou, China, 310018 \\ ${ }^{2}$ State Key Laboratory of Tree Genetics and Breeding, Chinese Academy of Forestry, Beijing, China, 100091 \\ ${ }^{3}$ Institute of Subtropical Forestry, Chinese Academy of Forestry, Hangzhou, China, 311400
}

\section{ABSTRACT}

Chemical preservatives have potential safety hazards, which may pose threats to human health. Safer biopreservatives are therefore urgently required. This study investigated the bacteriostatic activity and mechanism of Litsea mollis Hemsl. essential oil against Escherichia coli DH5 $\alpha$ and Salmonella spp. Antibacterial activity of Litsea mollis Hemsl. essential oil 9 (LMEO9) against E. coli DH5 $\alpha$ was observed (zone of inhibition was $5.0 \pm$ $0.2 \mathrm{~mm}$; minimum inhibitory concentration was $0.05 \%$ ). Increases in electrolyte, nucleic acid, and alkaline phosphatase leakage in LMEO9-treated bacteria suggested that the cell envelope had been damaged. Scanning and transmission electron microscopy also demonstrated morphological alterations and content leakage during LMEO9 treatment. According to the kill-time analysis and propidium iodide uptake assay, LMEO9 led to cell death. These results demonstrated that LMEO9, which could affect bacterial cell envelope structural integrity, is a low-cost biopreservative that could be useful for the dairy industry and in fresh storage.

Key words: antibacterial activity, Litsea mollis Hemsl. essential oil, mechanism of action, chemical composition

\section{INTRODUCTION}

Due to the existence of pathogenic microorganisms, food spoilage and food poisoning have led to huge economic losses and continued threats to human health (Yuan and Yuk, 2018). In the United States, 18 out-

Received January 13, 2019.

Accepted June 8, 2019.

*Corresponding authors: dafengsong@163.com and guqing2002@ hotmail.com breaks originating from organic foods occurred from 1992 to 2014 (56\% of these outbreaks occurred from 2010 to 2014), accounting for 779 cases of illness, 258 hospital stays, and 3 deaths (Harvey et al., 2016). According to World Health Organization statistics (WHO, 2015), non-typhoidal Salmonella and diarrheal Escherichia coli are the major causes of foodborne disease. Several synthetic antimicrobial compounds, including potassium sorbate and nitrate, have been shown to prevent food pathogen growth (Zhang et al., 2017a). These additives increase the shelf life of various products and decrease foodborne disease outbreaks. However, due to cumulative toxicity and increasing antibiotic resistance to conventional antiseptics, the use of natural antibacterial agents has gained intense research interest (Bajpai et al., 2013). Plant-derived essential oils (EO) have been shown to possess antioxidant (Bonilla et al., 2018), antimycotic (Dudoiu et al., 2017), and antibacterial (Diao et al., 2013) activities. Because the majority of EO are certified as generally recognized as safe (GRAS) substances by the US Food and Drug Administration (FDA; Kamatou and Viljoen, 2010), they represent attractive prospects for safer food preservation applications.

Litsea mollis Hemsl. belongs to the Lauraceae family and is primarily distributed in southwestern China. Litsea mollis Hemsl. essential oils (LMEO) from flowers and leaves are significant sources of citral, an ingredient of food spice (Wu et al., 2008). The global supply of Litsea oils is sufficient, and, compared with nisin, LMEO has a better cost benefit (Saikia et al., 2013). Although the chemical composition and antimicrobial activity of Vietnamese LMEO have been elucidated (Son et al., 2014; Nguyen et al., 2018), little information as to the effects of Chinese LMEO on Escherichia coli and Salmonella is known. Thus, we analyzed the chemical composition of Chinese LMEO, its bacteriostatic effects, and its mechanisms of action. The addition of LMEO can extend the shelf lives of dairy products such as pasteurized milk. 


\section{MATERIALS AND METHODS}

\section{Microbial Culture and Chemicals}

Nine strains of bacteria were used: 5 gram-negative strains (Salmonella spp., Pseudomonas aeruginosa ZFM1, Escherichia coli O104, E. coli O157, and E. coli DH5o), and 4 gram-positive strains (Enterococcus faecalis BM13, Listeria monocytogenes J4045, L. monocytogenes Clip11262, and Staphylococcus aureus ZFM1). All bacterial strains were provided by the Key Laboratory for Food Microbial Technology of Zhejiang Province (Hangzhou, China). Strains were stored in Microbank vials (Pro-Lab Diagnostics Inc., Richmond Hill, ON, Canada) at $-80^{\circ} \mathrm{C}$ and cultured at $37^{\circ} \mathrm{C}$ in Luria-Bertani (LB) medium or brain heart infusion (BHI) broth (Oxoid Ltd., Basingstoke, UK). All chemicals were of analytical grade.

\section{Essential Oil Extraction}

Three dried fruits of Litsea mollis Hemsl. from Wanzhou city, Chongqing Province, China, were ground using a micro-plant grinder, and the powder was hydrodistilled for $5 \mathrm{~h}$ using a Clevenger-type apparatus (Transparent Acrylic Glove Box, Plexiglass Lab Equipment, Jiangsu, China). Following extraction, LMEO was dried over anhydrous sodium sulfate, sealed, and preserved in the dark at $4^{\circ} \mathrm{C}$ before analysis. The EO were termed LMEO4, LMEO9, and LMEO28, respectively, according to the geographical area of origin of each sample.

\section{Analysis Using GC-MS}

Following dissolution in ethanol $(5 \mu \mathrm{L})$ and dehydration with anhydrous sodium sulfate, LMEO constituents were determined using TRACE GC Ultra gas chromatography (Thermo Fisher Scientific, Waltham, $\mathrm{MA})$ in a column $(60 \mathrm{~m} \times 0.25 \mathrm{~mm} ; 0.25-\mu \mathrm{m}$ film thickness) and mass selective detector (Polaris Q-Ion Trap MS). The mass selective detector was set to electron impact ionization $\left(230^{\circ} \mathrm{C}\right)$ mode, using a mass scan range of 50 to $500 \mathrm{~m} / z$ at $70 \mathrm{eV}$. The carrier gas was helium $(99.999 \%)$, at $1.5 \mathrm{~mL} / \mathrm{min}$ flow rate and a $1: 10$ split ratio. Injector and mass spectrometry transfer line temperatures were $220^{\circ} \mathrm{C}$ and $250^{\circ} \mathrm{C}$, respectively. The initial temperature of $50^{\circ} \mathrm{C}$ was increased to $170^{\circ} \mathrm{C}$ at $3^{\circ} \mathrm{C}$ per minute, topping out at $250^{\circ} \mathrm{C}$ for $3 \mathrm{~min}$. The EO composition was identified through a comparison of the GC retention index with standard specimens, statistics in the published literature, and the National Institute of Standards and Technology 08 Mass Spectral Library and Mass Spectral Search Program. The peak area was used to quantify the relative percentages of the separated compounds.

\section{Antibacterial Assays}

Determination of Bacterial Inhibition Zones. A slightly modified disk diffusion method served to quantify the diameter of inhibition zone (DIZ), as previously described (Diao et al., 2014a). Briefly, cultures were grown at $37^{\circ} \mathrm{C}$ for $24 \mathrm{~h}$ in LB liquid medium, after which $200-\mu \mathrm{L}$ inoculums (approximately $1 \times 10^{6} \mathrm{cfu} /$ $\mathrm{mL}$ ) and $10 \mathrm{~mL}$ of semi-solid medium were uniformly spread onto solid LB medium. Oxford cups were placed onto plates, and pure LMEO $(50 \mu \mathrm{L})$ was added. Plates were left at $37^{\circ} \mathrm{C}$ for $24 \mathrm{~h}$, and DIZ values $(\mathrm{mm})$ were measured with a ruler. Control treatment used was broth LB.

Determination of MIC and Minimum Bactericidal Concentrations. Minimum inhibitory concentrations and minimum bactericidal concentrations (MBC) were assessed using the microdilution method with some modifications (Wang et al., 2017). Briefly, LMEO was thoroughly dissolved in absolute ethanol to obtain serial dilutions in concentrations ranging from 1 to $100 \%$. Bacterial suspensions were added to obtain a final EO concentration of 0.01 to $1 \%$. Control tests were performed using $0.99 \%$ ethanol. The MIC represented the lowest concentration of EO at which no bacterial growth was visible after $24 \mathrm{~h}$ of cultivation at $37^{\circ} \mathrm{C}$. Suspensions that exhibited no visible growth were spread onto LB medium plates and subcultured at $37^{\circ} \mathrm{C}$ for $24 \mathrm{~h}$. The MBC represented the lowest concentration of EO at which no surviving colonies were observed.

\section{Kill-Time Analysis}

The LMEO9 possessed the broadest bacteriostatic spectrum and highest antibacterial activity. Escherichia coli DH5a and Salmonella spp. were selected as the model microorganisms for subsequent experiments because of higher sensitivity to LMEO9. Cells in the exponential growth phase were exposed to MIC and $\mathrm{MBC}$ of LMEO9 and cultivated for $24 \mathrm{~h}$ at $37^{\circ} \mathrm{C}$ with uniform shaking. Bacterial viability was quantified every $4 \mathrm{~h}$ through absorbance measurements at 600 $\mathrm{nm}$, performed on a microplate reader (Spectra Max 190, Molecular Devices LLC, San Jose, CA; Zengin and Baysal, 2014).

\section{Alkaline Phosphatase Leakage Assays}

Cell wall integrity was assessed through alkaline phosphatase (AKP) leakage assays (Song et al., 2018). 
For AKP assessment, bacteria were cultured overnight, and the inoculum was centrifuged at $6,000 \times g\left(4^{\circ} \mathrm{C}\right)$ for 8 min. Bacterial pellets were rinsed with PBS $(\mathrm{pH}$ 7.2), resuspended through vortexing, and washed 3 more times. Bacterial solutions were mixed with different concentrations (MIC and MBC) of LMEO9, and extracellular AKP levels were measured using a commercial AKP kit (Nanjing Jiancheng Bioengineering Institute, Nanjing, China) following the manufacturer's instructions. The control was $0.99 \%$ ethanol.

\section{Membrane Damage Assessment}

Relative Electrical Conductivity Assays. Membrane permeability was assessed through relative electrical conductivity (REC) using an electrical conductivity (EC) meter (Mettler-Toledo International Inc., Zurich, Switzerland; Diao et al., 2014b). For these assays, bacteria were cultured overnight and pelleted by centrifugation at $6,000 \times g\left(4^{\circ} \mathrm{C}\right)$ for $8 \mathrm{~min}$. The cell suspension was flushed with $5 \%$ glucose until it reached the same EC as the glucose solution. Isotonic bacteria were then treated with different concentrations of LMEO9 (control, MIC, and MBC), and the EC of each mix was identified as $\mathrm{L}_{1}$. Bacteria were then cultured at $37^{\circ} \mathrm{C}$ for $12 \mathrm{~h}$, with EC measured every $2 \mathrm{~h}$, marked as $\mathrm{L}_{2}$. The EC of bacteria in the same glucose solution treated in boiling water for 5 min was designated $\mathrm{L}_{0}$. The REC was quantified as follows:

$$
\operatorname{REC}(\%)=100 \times\left(\mathrm{L}_{2}-\mathrm{L}_{1}\right) \div \mathrm{L}_{0} .
$$

Nucleic Acid Leakage Assays. The extracellular concentration of nucleic acids indicates cell membrane integrity (Mutlu-Ingok and Karbancioglu-Guler, 2017). For nucleic acid assays, bacteria were pelleted by centrifuging at $6,000 \times g$ for $8 \mathrm{~min}\left(4^{\circ} \mathrm{C}\right)$ and resuspended in PBS. These experimental steps were repeated in triplicate. Harvested suspensions $(500 \mu \mathrm{L})$ were treated with various concentrations of LMEO9 (control, MIC, and $\mathrm{MBC}$ ) at $37^{\circ} \mathrm{C}$, and cultures were collected at 4 -h intervals. Optical density at $260 \mathrm{~nm}$ of supernatant was measured on a microplate reader (Spectra Max 190, Molecular Devices LLC).

\section{Propidium lodide Staining Assays}

Propidium iodide (PI) uptake is a standard cell death marker due to its ability to stain DNA by penetrating the cell membranes of dead or dying cells (Madhuri et al., 2009). Cell survival was assessed using a PI reagent kit (BBI Life Sciences Co., Ltd., Shanghai, China). Bacteria cultures that had been grown overnight were pelleted by centrifugation at $6,000 \times g$ for $8 \mathrm{~min}$, rinsed in PBS twice, and finally resuspended in assay buffer. We added PI staining solution and LMEO9 to bacterial suspensions, followed by incubation at $37^{\circ} \mathrm{C}$ for 5 to 30 min. We assessed PI staining via fluorescence microscopy (Oplenic Optronics Co., Jiangsu, China).

\section{Microscopic Observations}

Scanning Electron Microscopy. Bacterial morphology was observed using scanning electron microscopy following LMEO9 treatment. For scanning electron microscopy assessment, overnight cultures (5 $\mathrm{mL}$ ) were collected and treated with LMEO9 (control, $\mathrm{MBC}$ ). Suspensions were centrifuged at 4,000 $\times g$ for $10 \mathrm{~min}$ and fixed with $2.5 \%$ ( $\mathrm{vol} / \mathrm{vol}$ ) glutaraldehyde solution overnight at $4^{\circ} \mathrm{C}$. Cells were pelleted, rinsed in PBS for 15 min 3 times, and treated with $1 \%$ osmic acid for $1.5 \mathrm{~h}$. Washed cells were dehydrated in ethanol (30 to 100\%) and dried in liquid carbon dioxide. Following cathodic spraying with platinum, morphological observations were assessed by scanning electron microscopy (Hitachi TM1000, Hitachi Ltd., Tokyo, Japan).

Transmission Electron Microscopy. Treatments were performed as for scanning electron microscopy, and samples were dehydrated in $30,50,80,90$, and $95 \%$ ethanol for $15 \mathrm{~min}$, followed by exposure to $100 \%$ ethanol and $100 \%$ acetone, each for $20 \mathrm{~min}$. Following hydration, an embedding reagent was added to the specimen for $12 \mathrm{~h}$ at $70^{\circ} \mathrm{C}$. Stained cells were imaged using a transmission electron microscope (Hitachi H-7650, Hitachi Ltd.).

\section{Statistical Analysis}

All experiments were performed in triplicate. Data shown are mean \pm standard deviation (SD). Significance between groups was evaluated using one-way ANOVA and Duncan's test. The cutoff for statistical significance set at $P<0.05$.

\section{RESULTS AND DISCUSSION}

\section{Chemical Composition of LMEO}

The composition of LMEO was identified by GC-MS (Supplemental Table S1: https://doi.org/10.3168/jds .2019-16292). The main components of LMEO4 were neral (46.66\%), followed by geranial (36.52\%). Likewise, LMEO9 and LMEO28 were mainly composed of neral (36.64 and $42.44 \%$, respectively) and geranial (37.20 and $48.95 \%$, respectively), similar to LMEO derived from Taiwan (Ho et al., 2010) and southern regions of 
Table 1. Bacterial growth inhibition zones ${ }^{1}(\mathrm{~mm})$ of Litsea mollis Hemsl. essential oils (LMEO) from 3 regions of China

\begin{tabular}{lccc}
\hline Bacterial strain & LMEO4 & LMEO9 & LMEO28 \\
\hline Gram negative & & & \\
Salmonella spp. & $4.1 \pm 0.9^{\mathrm{a}}$ & $4.2 \pm 0.2^{\mathrm{a}}$ & $3.6 \pm 0.8^{\mathrm{a}}$ \\
Escherichia coli O157 & $4.0 \pm 0.6^{\mathrm{b}}$ & $2.6 \pm 0.5^{\mathrm{b}}$ & $4.6 \pm 0.7^{\mathrm{b}}$ \\
E. coli DH5 $\alpha$ & $3.0 \pm 0.6^{\mathrm{c}}$ & $5.0 \pm 0.2^{\mathrm{c}}$ & $3.0 \pm 0.6^{\mathrm{c}}$ \\
E. coli O104 & 0 & $1.4 \pm 0.3^{\mathrm{d}}$ & $1.2 \pm 0.2^{\mathrm{d}}$ \\
Pseudomonas aeruginosa ZFM1 & 0 & 0 & 0 \\
Gram positive & 0 & 0 & 0 \\
Enterococcus faecalis BM13 & 0 & 0 & 0 \\
Listeria monocytogenes J4045 & 0 & 0 & 0 \\
L. monocytogenes Clip 11262 & 0 & 0 & 0 \\
Staphylococcus aureus ZFM1 & 0 & 0 & \\
\hline
\end{tabular}

${ }^{a-d}$ Different lowercase superscripts in the same columns represent statistically significant differences between means $(P<0.05)$.

${ }^{1}$ Diameters of inhibition zones were determined by modified disk diffusion method. Values indicate the average $\pm \mathrm{SD}$ of experiments performed in triplicate. Diameter of inhibition zone values have been calculated minus the diameter of Oxford cup $(8 \mathrm{~mm})$.

China (Wang and Liu, 2010). The antibacterial activity of the compounds was ranked as follows: phenol $>$ aldehyde $>$ ketone $>$ alcohol $>$ ether $>$ hydrocarbon (Nguyen et al., 2018). Aldehyde was the dominant component of LMEO, which presumably contributes to its noticeable antibacterial abilities as a food preservative (Li et al., 2013; Sun et al., 2015). A different inhibitory activity against $E$. coli was observed between LMEO (MIC $0.01 \%$ to $0.5 \%$ ) and Indian Lauraceae EO (MIC approximately 0.003 to $0.02 \%$ ), which is mainly composed of sabinene, and Vietnamese LMEO (MIC 0.003 to $0.006 \%, 1,8$-cineole or linalool type) was more potent against Salmonella Typhimurium compared with its Chinese counterpart (MIC 0.5\%). This was due to less noticeable bacteriostatic effect of citral than that of sabinene, 1,8-cineole, and linalool (Saikia et al., 2013; Nguyen et al., 2018).

\section{Determination of Antibacterial Efficacy}

The DIZ values of LMEO were determined using the disk diffusion method. The highest bacteriostatic effect was observed in LMEO9 (Table 1), with the highest levels of antimicrobial activity against $E$. coli DH5a $(5.0 \mathrm{~mm})$ and Salmonella spp. (4.2 mm). Against E. coli O157 and E. coli O104, LMEO9 displayed moderate activity, with DIZ values of 2.6 and $1.4 \mathrm{~mm}$, respectively. Against E. faecalis BM13, L. monocytogenes J4045, L. monocytogenes Clip 11262, Staph. aureus ZFM1, and $P$. aeruginosa ZFM1, LMEO9 displayed no inhibitory activity. Thus, LMEO9 primarily inhibits gram-negative bacteria.

Measurements of MIC and MBC are displayed in Table 2. The MIC of Salmonella and E. coli O157 were 0.5 and $0.1 \%$, whereas the MBC was $1 \%$ for both bacterial strains. Against E. coli DH5 2 , LMEO9 displayed potent antimicrobial activity, with an MIC value of $0.05 \%$ and an MBC of $0.1 \%$. The efficacy of Litsea $\mathrm{EO}$ against E. coli $\mathrm{O} 104$ was negligible.

Antibacterial screening results show the inhibition of primarily gram-negative bacteria by LMEO9. Pseudomonas aeruginosa showed no bacteriostatic activity, consistent with previous studies that found Pseudomonas to be the least sensitive to EO (Burt, 2004). The

Table 2. Activity of Litsea mollis Hemsl. essential oils (LMEO) from 3 regions of China against gram-negative bacteria; results determined by modified microdilution method

\begin{tabular}{|c|c|c|c|c|c|c|}
\hline \multirow[b]{2}{*}{ Bacterial strain } & \multicolumn{2}{|c|}{ LMEO4 } & \multicolumn{2}{|c|}{ LMEO9 } & \multicolumn{2}{|c|}{ LMEO28 } \\
\hline & $\begin{array}{c}\mathrm{MIC}^{1} \\
(\%)\end{array}$ & $\begin{array}{c}\mathrm{MBC}^{2} \\
(\%)\end{array}$ & $\begin{array}{c}\mathrm{MIC} \\
(\%)\end{array}$ & $\begin{array}{c}\mathrm{MBC} \\
(\%)\end{array}$ & $\begin{array}{c}\mathrm{MIC} \\
(\%)\end{array}$ & $\begin{array}{c}\mathrm{MBC} \\
(\%)\end{array}$ \\
\hline Salmonella spp. & 0.5 & 1 & 0.5 & 1 & 0.5 & 1 \\
\hline Escherichia coli $\mathrm{O} 157$ & 0.01 & 0.05 & 0.1 & 1 & 0.05 & 0.1 \\
\hline E. coli $\mathrm{DH} 5 \alpha$ & 0.05 & 0.1 & 0.05 & 0.1 & 0.5 & 1 \\
\hline E. coli $\mathrm{O} 104$ & $>1$ & $>1$ & $>1$ & $>1$ & $>1$ & $>1$ \\
\hline
\end{tabular}

${ }^{1} \mathrm{MIC}(\%, \mathrm{vol} / \mathrm{vol})=$ minimum inhibitory concentration.

${ }^{2} \mathrm{MBC}(\%, \mathrm{vol} / \mathrm{vol})=$ minimum bactericidal concentration. 

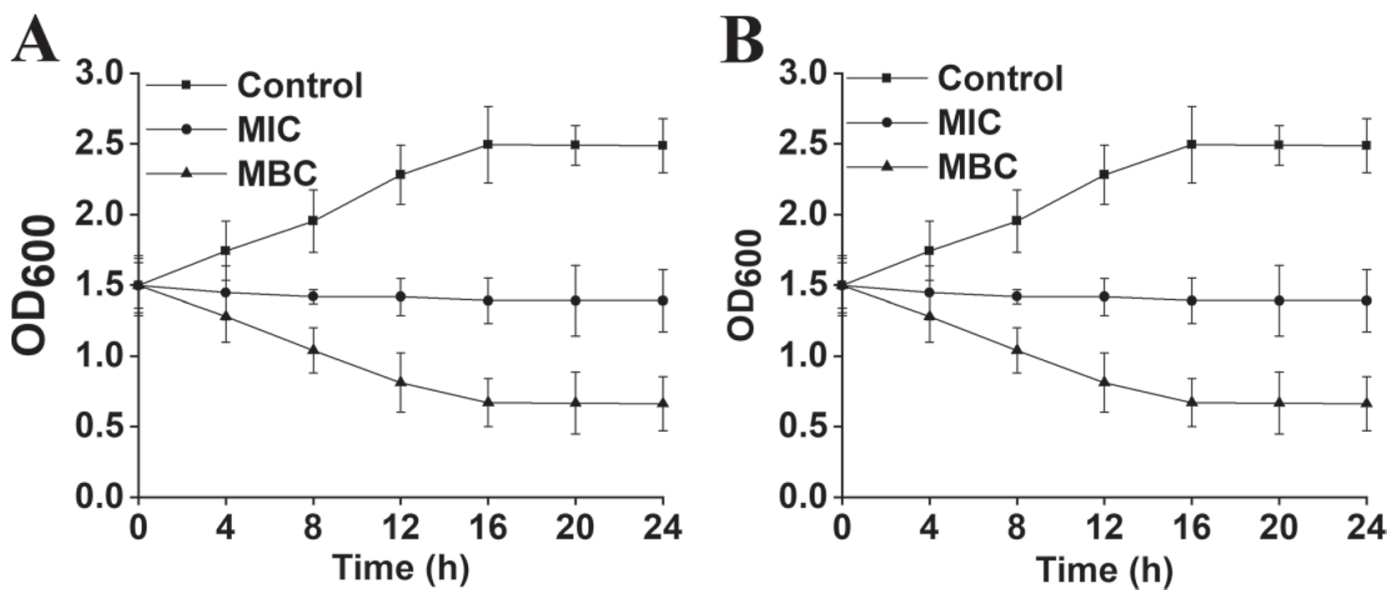

Figure 1. Effects of Litsea mollis Hemsl. essential oil (LMEO9) on viability of Escherichia coli DH5a (A) and Salmonella spp. (B). Cell viability was assessed by absorbance measurements of optical density at $600 \mathrm{~nm}\left(\mathrm{OD}_{600}\right)$, recorded on a molecular microplate reader (Spectra Max 190, Molecular Devices LLC, San Jose, CA). Control group (squares) represents the bacteria exposed to 0.99\% ethanol. Minimum inhibitory concentration (MIC, circles) and minimum bactericidal concentration (MBC, triangles) represent bacterial levels following treatments of LMEO9 at corresponding concentrations. Data are expressed as mean $\pm \mathrm{SD}$, analyzed using one-way ANOVA and Duncan's test; $P<0.05$ was the cutoff for statistical significance.

bacteriostatic activity of LMEO may have been due to cell wall disruption (Nazzaro et al., 2013). Many studies currently suggest that, compared with grampositive bacteria, gram-negative bacteria may be more resistant to EO because the high levels of cell wall LPS in gram-negative bacteria could inhibit influx of hydrophobic compounds (Calo et al., 2015). However, studies suggest that some EO are more active against gram-negative bacteria (Devi et al., 2010; Meng et al., 2016; Zhang et al., 2017a). These differences may be attributable to the varying constituents of $\mathrm{EO}$ and to higher levels of intracellular ATP leaking into the incubation solution following inhibitor exposure (Cui et al., 2015). Additionally, LMEO exhibits different bacteriostatic activity against E. coli O104, E. coli O157, and E. coli DH5a. The monoterpenes contained in EO exert antimicrobial effects that are dependent on membrane lipid composition and the net surface charge derived from LPS for gram-negative bacteria (Saikia et al., 2013). The diversity of the O-antigen in LPS allows it to act across $E$. coli strains, which may partly explain its varying potency (DebRoy et al., 2011; Shashkov et al., 2015). Furthermore, the composition values of neral and geranial are similar between EO (Supplemental Table S1; https://doi.org/10.3168/jds .2019-16292). In spite of previous conclusions that oxygenated monoterpenes account for the majority of the antibacterial activity of Litsea (Saikia et al., 2013), our results suggest that other small fractions of components also affect EO activity. Kalemba and Kunicka (2003) concluded that ratios of constituents, rather than their quantities, account for the efficacy of EO.

\section{Kill-Time Curves}

According to the susceptibility of the pathogens, $E$. coli DH5a and Salmonella served as model microbes for

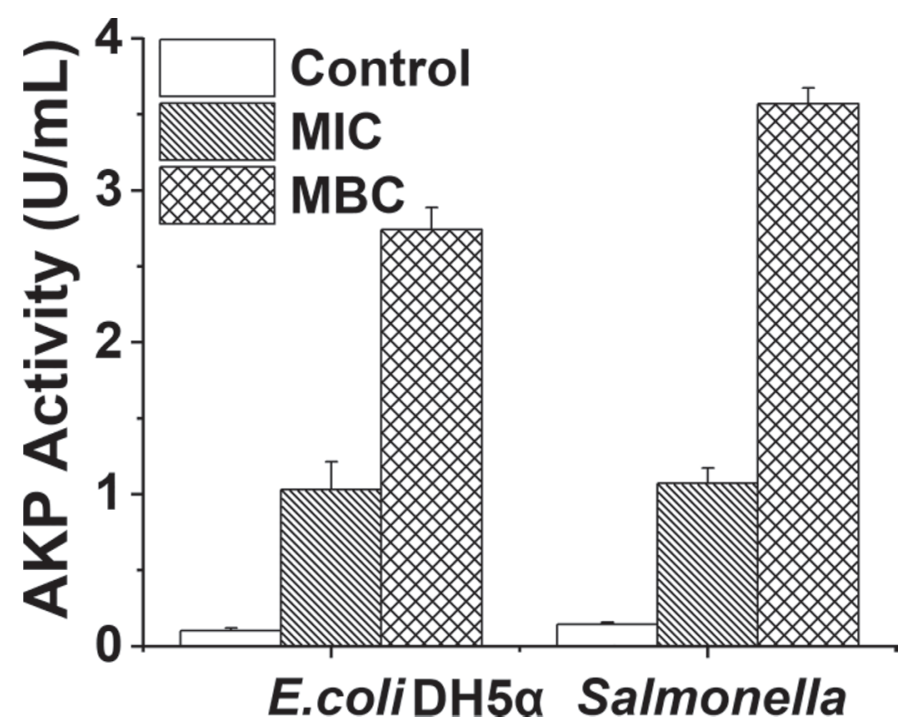

Figure 2. Effect of Litsea mollis Hemsl. essential oil (LMEO9) on damage to cell wall of Escherichia coli DH5a and Salmonella spp. Extracellular alkaline phosphatase (AKP) activity was determined using a commercial AKP kit (Nanjing Jiancheng Bioengineering Institute, Nanjing, China). Control group (unshaded bars) represents the bacteria exposed to $0.99 \%$ ethanol. Minimum inhibitory concentration (MIC, diagonal stripes) and minimum bactericidal concentration (MBC, cross-hatching) represent the strains following treatments of LMEO9 at corresponding concentrations. Data are expressed as mean $\pm \mathrm{SD}$, analyzed using one-way ANOVA and Duncan's test; $P<0.05$ was the cutoff for statistical significance. 

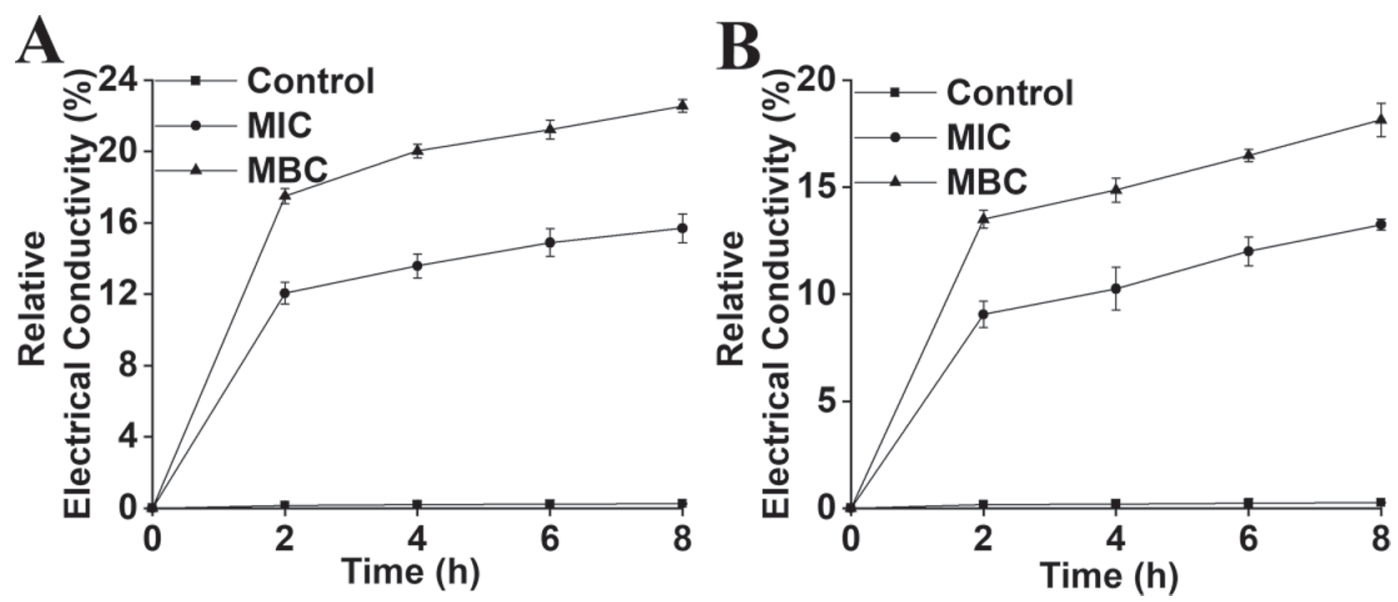

Figure 3. Effect of Litsea mollis Hemsl. essential oil (LMEO9) on cell membrane permeability of Escherichia coli DH5a (A) and Salmonella spp. (B). The relative electrical conductivity (REC) was measured using a Mettler Toledo (Columbus, OH) conductivity meter. Control group (squares) represents the bacteria with $0.99 \%$ ethanol treatment. Minimum inhibitory concentration (MIC, circles) and minimum bactericidal concentration (MBC, triangles) represent the strains following treatments of LMEO9 at corresponding concentrations. Data are expressed as mean $\pm \mathrm{SD}$, analyzed using one-way ANOVA and Duncan's test; $P<0.05$ was the cutoff for statistical significance.

further exploration into the mode of action of LMEO9. Compared with controls, the number of viable $E$. coli DH5 $\alpha$ exposed to the MIC of LMEO9 declined slightly during the first $4 \mathrm{~h}$ of treatment and then remained constant (Figure 1A). Unlike the variation trend of optical density at $600 \mathrm{~nm}$ at MIC, in treatments at MBC, a decrease of $59.5 \%$ from 1.501 to 0.608 over the first $16 \mathrm{~h}$ of treatment occurred, followed by a more gradual decrease over time. The loss of viability of Salmonella (Figure 1B) was not statistically significantly different from that of $E$. coli.

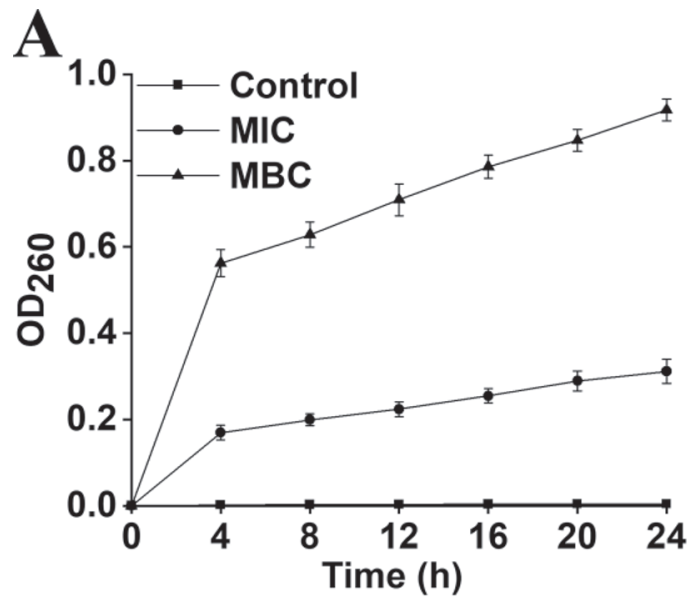

These data strongly suggest that LMEO9 is a natural preservative with bactericidal effects that are dependent on the time of exposure and concentration. Similar to these findings, Litsea mollis leaf EO from Vietnam have been shown to inhibit bacterial growth (Nguyen et al., 2018).

\section{Cell Wall Damage Evaluation}

Alkaline phosphatase cannot be detected in bacterial culture medium unless the cell wall has been destroyed

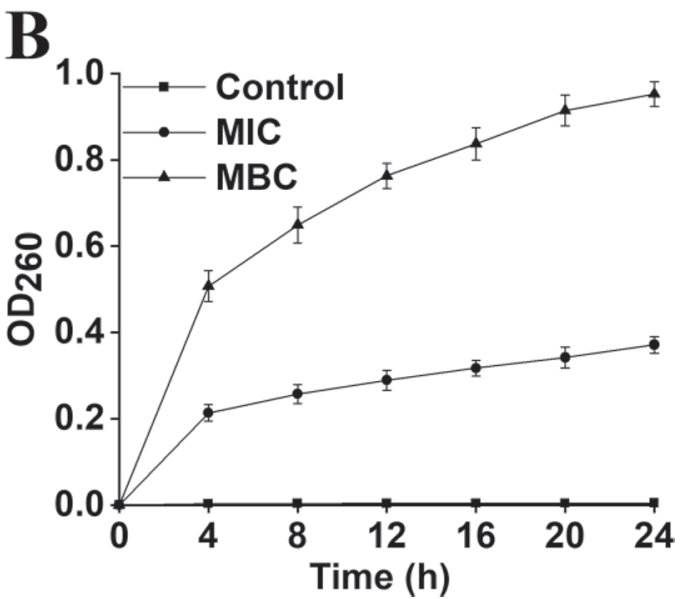

Figure 4. Effect of Litsea mollis Hemsl. essential oil (LMEO9) on cell membrane integrity of Escherichia coli DH5a (A) and Salmonella (B). The concentration of extracellular nucleic acid was determined by absorbance measurements at $260 \mathrm{~nm}\left(\mathrm{OD}_{260}\right)$, recorded on a molecular microplate reader (Spectra Max 190, Molecular Devices LLC, San Jose, CA). Control group (squares) represents the bacteria exposed to 0.99\% ethanol. Minimum inhibitory concentration (MIC, circles) and minimum bactericidal concentration (MBC, triangles) represent the strains following treatments of LMEO9 at corresponding concentrations. Data were expressed as mean \pm SD, analyzed using one-way ANOVA and Duncan's test; $P<0.05$ was the cutoff for statistical significance. 
(Xu et al., 2016). The activity of AKP significantly increased (approximately 7 -fold) when bacteria were treated with LMEO9 at MIC (Figure 2). In addition, the LMEO9 at MBC produced a larger increase in AKP compared with MIC, with the largest effects observed in Salmonella (0.1439 to $3.5709 \mathrm{U} / \mathrm{mL}$ ). The increased AKP activity confirmed that LMEO9 damaged the bacterial cell wall. Therefore, LMEO9 exerts its bactericidal effect through a loss of cell wall integrity, allowing microbes and hydrolytic enzymes to enter cells, inducing cell death (Wang et al., 2017).

\section{Cell Membrane Damage Evaluation}

Cell Membrane Permeability Analysis. Bacterial membrane permeability was assessed using electrolyte leakage assays (Figure 3). Although control cells displayed a small increase in REC due to normal cell death, the REC of experimental groups displayed sig- nificantly elevated values within the first $2 \mathrm{~h}$, which then stabilized (22.6 and $18.1 \%$ for E. coli DH5 $\alpha$ and Salmonella, respectively) by $8 \mathrm{~h}$. We found that $\mathrm{K}^{+}$, $\mathrm{Na}^{+}$, and $\mathrm{Ca}^{2+}$ had leaked from cells, indicating membrane permeability due to LMEO9. Ion leakage disrupts the electrochemical gradients required for ion channel activity and their associated metabolic functions, bringing about cell death (Patra et al., 2015). Alpinia gunianensis-leaf EO has similarly been shown to induce abnormal release of small molecules from bacterial cells (Deng et al., 2016).

Cell Membrane Integrity Analysis. Cytoplasmic membrane integrity was further assessed through nucleic acid leakage assays. The absorbance values measured at $260 \mathrm{~nm}$ rapidly increased over the first $4 \mathrm{~h}$ of LMEO9 treatment and reached sustained levels at 20 to $24 \mathrm{~h}$ (Figure 4). The time required to achieve an equilibrium of nucleic acids was longer than that of other small molecules, which reveals the ability of LMEO to de-
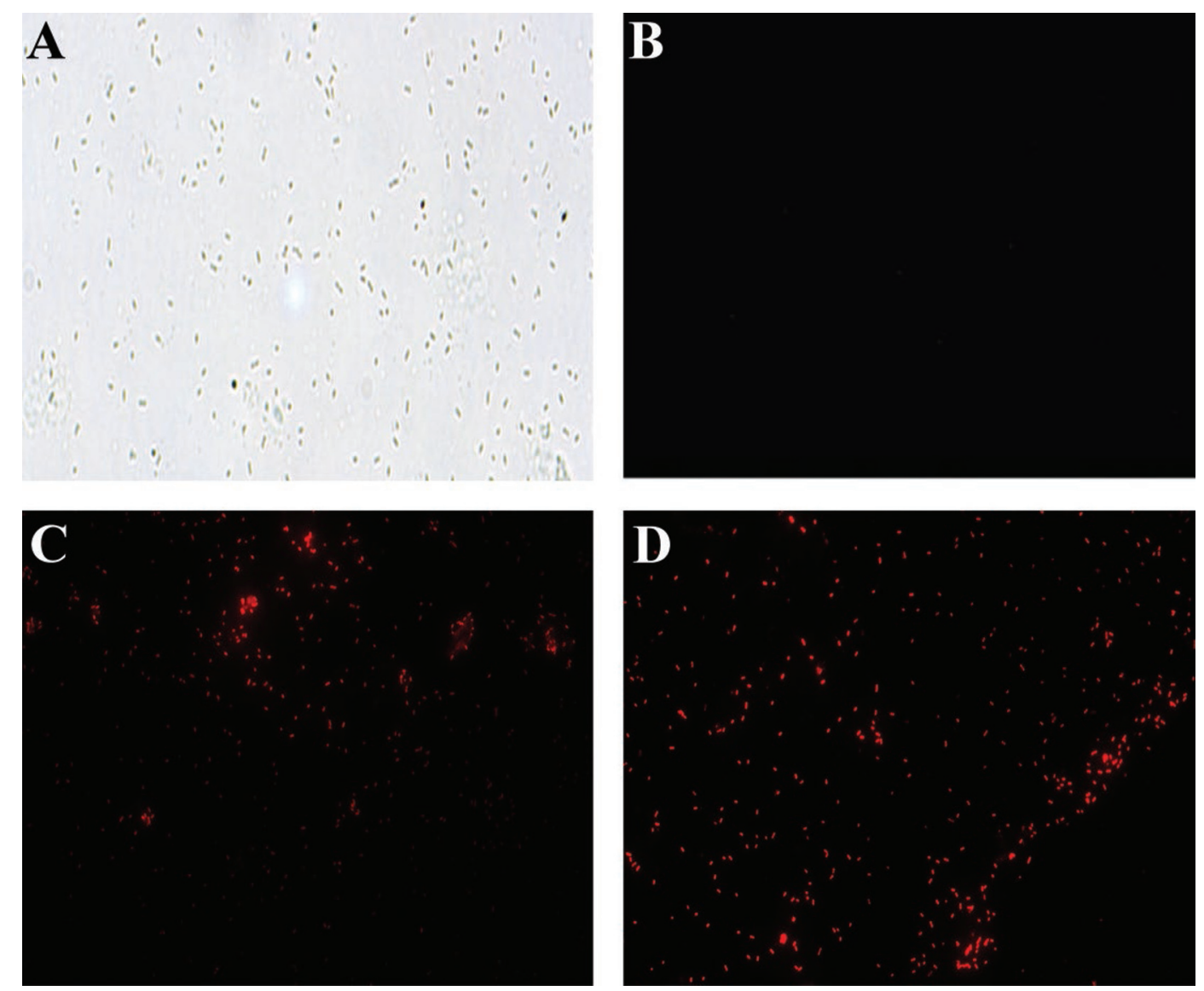

Figure 5. Cell viability of Escherichia coli DH5 $\alpha$ under microscopic observation (400× magnification). Fluorescence was determined using a propidium iodide (PI) reagent kit (BBI Life Sciences Co. Ltd., Shanghai, China); fluorescence indicates bacterial death. Optical image of (A)

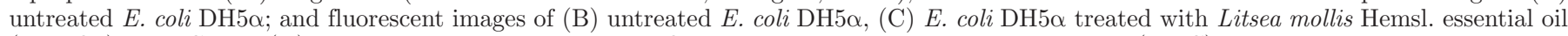
(LMEO9) at MIC; and (D) E. coli DH5 $\alpha$ treated with LMEO9 at minimum bactericidal concentration (MBC). 
stroy cytomembrane continually. (Figure 3). Additionally, LMEO9 generated more obvious alterations to the optical density at $260 \mathrm{~nm}$ at MBC compared with that caused by LMEO at MIC. These data could be due to cell membrane rupture and nucleic acid release into the medium in the presence of LMEO9. Loss of intracellular nucleic acids leads to decreased bacterial DNA replication, transcription, and translation, ultimately leading to cell death (Zhang et al., 2017a).

\section{Fluorescence Microscopy Viability Evaluation}

Propidium iodide is a fluorescent dye that can access the interior of dead cells and stain DNA (Zhang et al., 2017c). An increase in PI fluorescence intensity, indicating the presence of dead bacteria, was observed in the presence of increasing concentrations of LMEO9 (Figures 5C, D). Optical (Figure 5A) and fluorescent microscope (Figure 5B) images revealed that untreated E. coli DH5a appeared healthy in the culture medium. Thus, LMEO9 treatment induced bacterial cell death, most notably at higher concentrations, supporting the data from kill-time curves. Similar bactericidal effects were observed for curcumin I against E. coli (Tyagi et al., 2015).

\section{Morphological Transformation}

Images from scanning electron microscopy confirmed extensive morphological alterations to E. coli $\mathrm{DH} 5 \alpha$
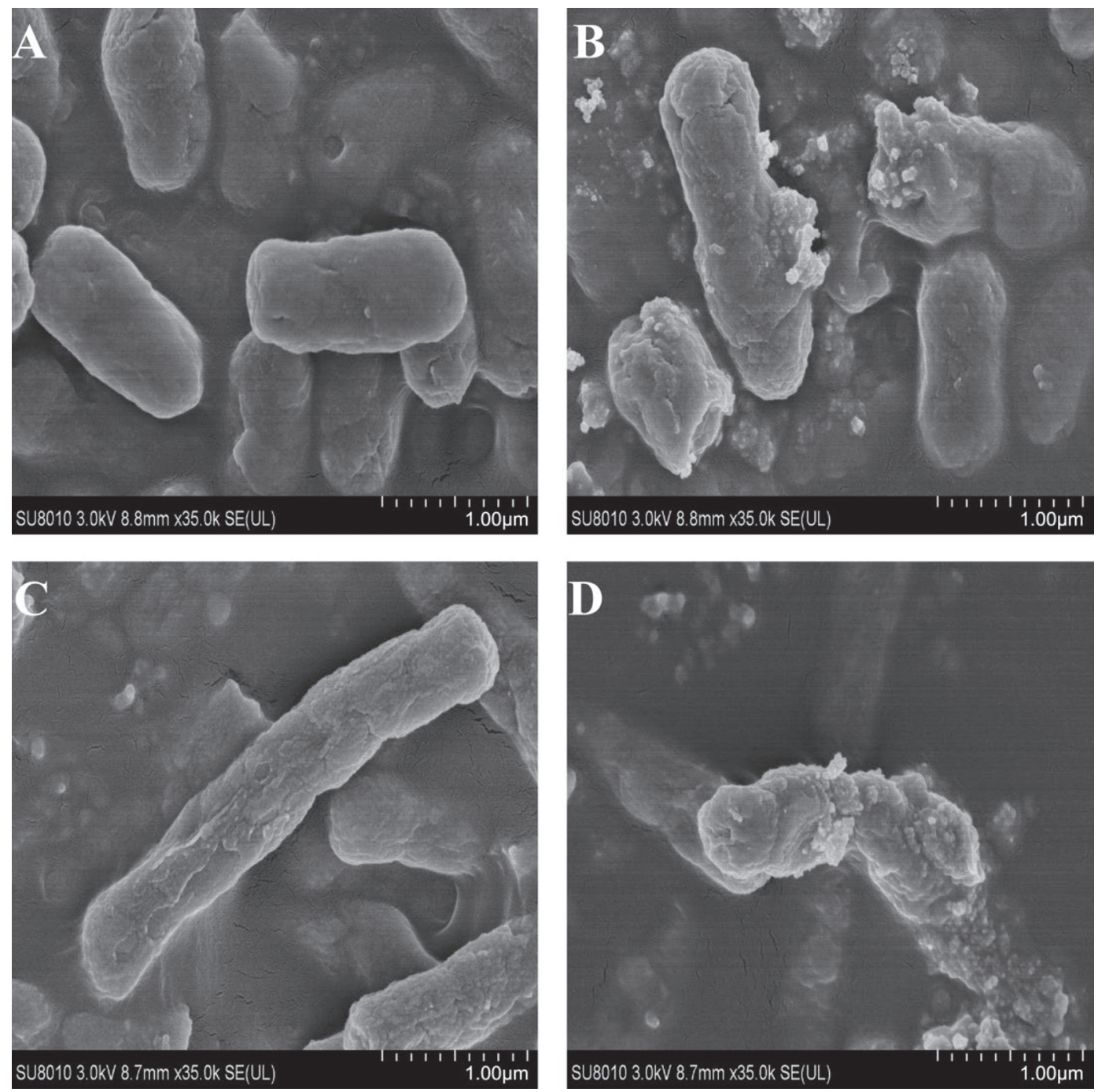

Figure 6. Morphological alterations in cell surface of Escherichia coli DH5 $\alpha$ and Salmonella. Observation was performed using scanning electron microscopy $(35,000 \times$ magnification). (A) Untreated E. coli DH5 $;$; (B) E. coli DH5 $\alpha$ treated with Litsea mollis Hemsl. essential oil (LMEO9) at minimum bactericidal concentration (MBC); (C) untreated Salmonella; (D) Salmonella treated with LMEO9 at MBC. 
and Salmonella. Untreated cells (Figure 6A and C) were regular, rod shaped, and appeared intact, whereas LMEO9 at MBC (Figure 6B and D) led to pore formation, cell lysis, and release of intracellular materials. Following LMEO9 treatment, extensive structural changes, including surface collapse and heterogeneous cytosol, were observed, as illustrated in Figure 7B and D. Transmission electron microscopy micrographs of the control group showed a dense cytoplasm and characteristic cell morphology (Figure 7A and C). Thus, microscopic evaluations revealed that LMEO9 exerted bactericidal activity by influencing cell envelope integrity, consistent with our cell wall and membrane damage data. Various plant extracts display a similar ability to induce physical changes in bacterial cell walls and membranes (Shan et al., 2007; Tyagi et al., 2015; Yuan et al., 2015). However, LMEO9 produced more notable morphological alterations in E. coli than those observed for black pepper EO under identical treatment conditions (Zhang et al., 2017b).

\section{CONCLUSIONS}

We demonstrated that LMEO displays strong bacteriostatic effects against E. coli DH5 $\alpha$ and Salmonella spp. The antimicrobial activity of LMEO was elicited through physical and morphological damage of the bacteria cell envelope. We observed AKP, electrolyte, and nucleic acid release into the extracellular medium following LMEO9 treatment. These alterations led to loss of cell viability, supported by results from kill-time curves and fluorescent images. Analysis via GC-MS showed the main components of LMEO4, LMEO9, and LMEO28 to be citral (geranial and neral). The antibacterial activity of LMEO at lower level of neral is better than those containing more neral. To apply Chi-
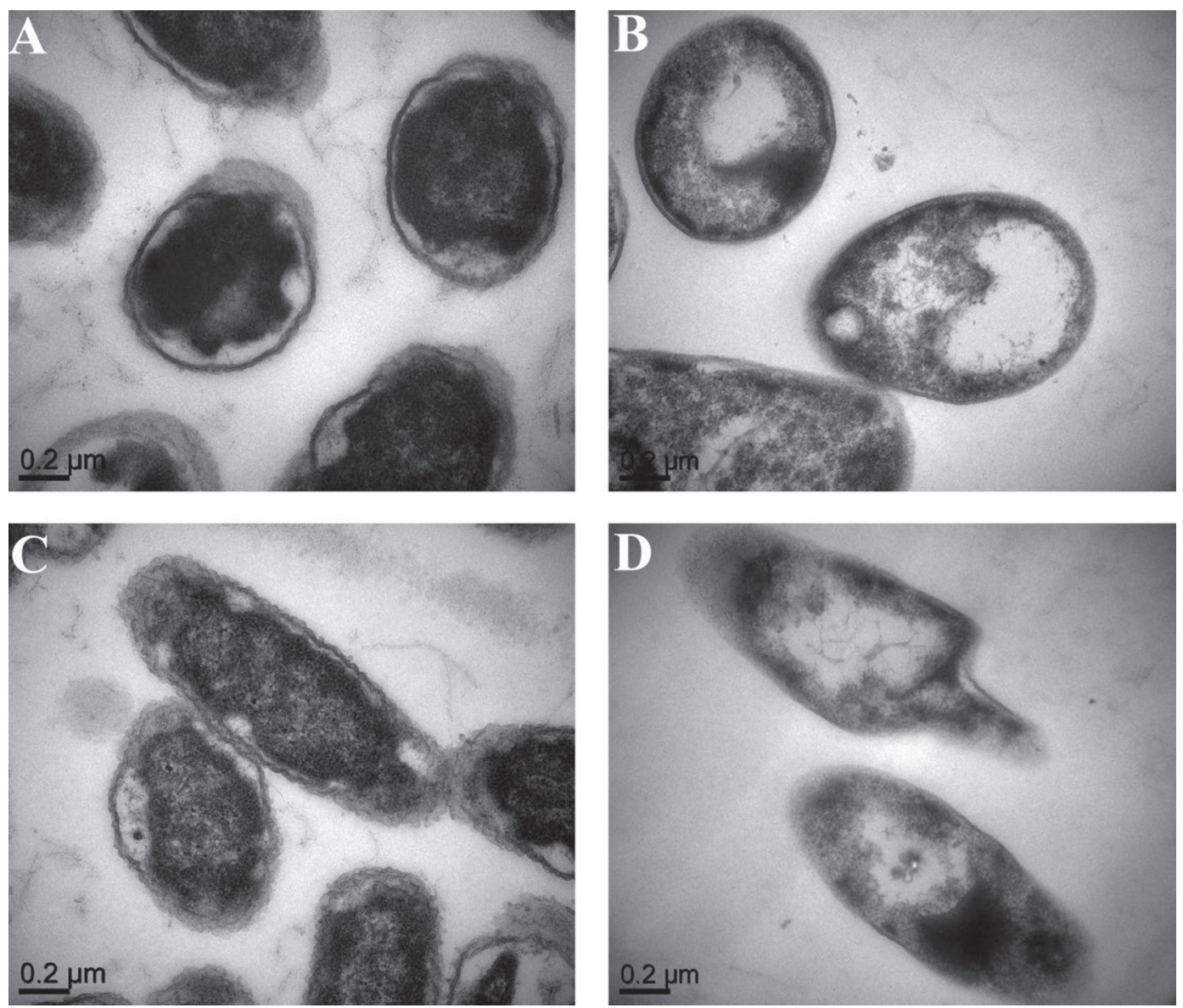

Figure 7. Intracellular alterations to Escherichia coli DH5 $\alpha$ and Salmonella. Observation was performed using transmission electron micros-

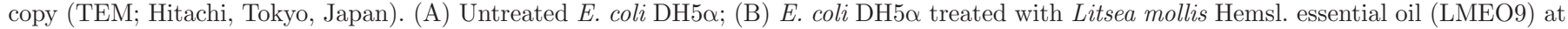
minimum bactericidal concentration (MBC); (C) untreated Salmonella; (D) Salmonella treated with LMEO9 at MBC. 
nese LMEO to the biopreservative field, investigation of its synergism with other antimicrobial compounds, interaction with food compositions, and toxicological evaluations are now required.

\section{ACKNOWLEDGMENTS}

This research was funded by the Natural Science Foundation of Zhejiang Province (No. LY18C06004, Hangzhou, China) and the National Natural Science Foundation of China (Beijing; No. 31871775).

\section{REFERENCES}

Bajpai, V. K., A. Sharma, and K. Baek. 2013. Antibacterial mode of action of Cudrania tricuspidata fruit essential oil, affecting membrane permeability and surface characteristics of food-borne pathogens. Food Control 32:582-590. https://doi.org/10.1016/j .foodcont.2013.01.032.

Bonilla, J., T. Poloni, R. V. Lourenco, and P. J. A. Sobral. 2018. Antioxidant potential of eugenol and ginger essential oils with gelatin/ chitosan films. Food Biosci. 23:107-114. https://doi.org/10.1016/ j.fbio.2018.03.007.

Burt, S. 2004. Essential oils: Their antibacterial properties and potential applications in foods-A review. Int. J. Food Microbiol. 94:223-253. https://doi.org/10.1016/j.ijfoodmicro.2004.03.022.

Calo, J. R., P. G. Crandall, C. A. O'Bryan, and S. C. Ricke. 2015. Essential oils as antimicrobials in food systems - A review. Food Control 54:111-119. https://doi.org/10.1016/j.foodcont.2014.12.040.

Cui, H., X. Zhang, H. Zhou, C. Zhao, and L. Lin. 2015. Antimicrobia activity and mechanisms of Salvia sclarea essential oil. Bot. Stud. 56. https://doi.org/10.1186/s40529-015-0096-4.

DebRoy, C., E. Roberts, and P. M. Fratamico. 2011. Detection of O antigens in Escherichia coli. Anim. Health Res. Rev. 12:169-185. https://doi.org/10.1017/S1466252311000193.

Deng, J., B. He, D. He, and Z. Chen. 2016. A potential biopreservative: Chemical composition, antibacterial and hemolytic activities of leaves essential oil from Alpinia guinanensis. Ind. Crops Prod. 94:281-287. https://doi.org/10.1016/j.indcrop.2016.09.004.

Devi, K. P., S. A. Nisha, R. Sakthivel, and S. K. Pandian. 2010. Eugenol (an essential oil of clove) acts as an antibacterial agent against Salmonella typhi by disrupting the cellular membrane. J. Ethnopharmacol. 130:107-115. https://doi.org/10.1016/j.jep.2010 .04 .025 .

Diao, W. R., Q. P. Hu, S. S. Feng, W. Q. Li, and J. G. Xu. 2013. Chemical composition and antibacterial activity of the essential oil from green huajiao (Zanthoxylum schinifolium) against selected foodborne pathogens. J. Agric. Food Chem. 61:6044-6049. https:/ /doi.org/10.1021/jf4007856.

Diao, W. R., Q. P. Hu, H. Z. Zhang, and J. G. Xu. 2014a. Chemical composition, antibacterial activity and mechanism of action of essential oil from seeds of fennel (Foeniculum vulgare Mill.). Food Control 35:109-116. https://doi.org/10.1016/j.foodcont.2013 .06 .056

Diao, W. R., L. L. Zhang, S. S. Feng, and J. G. Xu. 2014b. Chemical composition, antibacterial activity, and mechanism of action of the essential oil from Amomum kravanh. J. Food Prot. 77:1740-1746.

Dudoiu, R., C. Petrisor, V. Fatu, C. Lupu, and S. Cristea. 2017. Antimycotic activity of Thymus vulgaris essential oil against cereals storage moulds. J. Biotechnol. 256:S70. https://doi.org/10.1016/j .jbiotec.2017.06.1038.

Harvey, R. R., C. M. Zakhour, and L. H. Gould. 2016. Foodborne disease outbreaks associated with organic foods in the United States. J. Food Prot. 79:1953-1958.

Ho, C. L., O. Jie-Ping, Y. C. Liu, C. P. Hung, M. C. Tsai, P. C. Liao, E. I. Wang, Y. L. Chen, and Y. C. Su. 2010. Compositions and in vitro anticancer activities of the leaf and fruit oils of Litsea cubeba from Taiwan. Nat. Prod. Commun. 5:617-620.

Kalemba, D., and A. Kunicka. 2003. Antibacterial and antifungal properties of essential oils. Curr. Med. Chem. 10:813-829.

Kamatou, G. P. P., and A. M. Viljoen. 2010. A review of the application and pharmacological properties of alpha-bisabolol and alphabisabolol-rich oils. J. Am. Oil Chem. Soc. 87:1-7. https://doi.org/ 10.1007/s11746-009-1483-3.

Li, W., Q. Shi, C. Mo, Y. Ouyang, Y. Chen, and S. Duan. 2013. Chemical composition and antimicrobial activity of several typical essential oils. Microbiology China. 40: 2128-2137. http://qikan .cqvip.com/Qikan/Article/Detail?id=47966402.

Madhuri, T., S. K. Shireen, D. Venugopal, R. Ghosh, B. Gadepalli, Dhawan, and K. Mukhopadhyay. 2009. In vitro antimicrobial activity of alpha-melanocyte stimulating hormone against major human pathogen Staphylococcus aureus. Peptides 30:1627-1635. https://doi.org/10.1016/j.peptides.2009.06.020.

Meng, X., D. Li, D. Zhou, D. Wang, Q. Liu, and S. Fan. 2016. Chemical composition, antibacterial activity and related mechanism of the essential oil from the leaves of Juniperus rigida Sieb. et Zucc against Klebsiella pneumoniae. J. Ethnopharmacol. 194:698-705. https://doi.org/10.1016/j.jep.2016.10.050.

Mutlu-Ingok, A., and F. Karbancioglu-Guler. 2017. Cardamom, cumin, and dill weed essential oils: Chemical compositions, antimicrobial activities, and mechanisms of action against Campylobacter spp. Molecules 22:1191. https://doi.org/10.3390/molecules22071191.

Nazzaro, F., F. Fratianni, L. D. Martino, R. Coppola, and V. D. Feo. 2013. Effect of essential oils on pathogenic bacteria. Pharmaceuticals (Basel). 6:1451-1474. https://doi.org/10.3390/ph6121451.

Nguyen, H. V., J. C. Meile, M. Lebrun, D. Caruso, S. Chu-Ky, and S. Sarter. 2018. Litsea cubeba leaf essential oil from Vietnam: Chemical diversity and its impacts on antibacterial activity. Lett. Appl. Microbiol. 66:207-214. https://doi.org/10.1111/lam.12837.

Patra, J. K., G. Das, and K. Baek. 2015. Antibacterial mechanism of the action of Enteromorpha linza L. essential oil against Escherichia coli and Salmonella typhimurium. Bot. Stud. 56. https:// doi.org/10.1186/s40529-015-0093-7.

Saikia, A. K., D. Chetia, M. D'Arrigo, A. Smeriglio, T. Strano, and G. Ruberto. 2013. Screening of fruit and leaf essential oils of Litsea cubeba Pers. from north-east India - Chemical composition and antimicrobial activity. J. Essent. Oil Res. 25:330-338. https://doi .org/10.1080/10412905.2013.775081.

Shan, B., Y. Cai, J. D. Brooks, and H. Corke. 2007. Antibacterial properties and major bioactive components of cinnamon stick (Cinnamomum burmannii): Activity against foodborne pathogenic bacteria. J. Agric. Food Chem. 55:5484-5490. https://doi.org/10 $.1021 /$ jf070424d.

Shashkov, A. S., M. Wang, E. M. Turdymuratov, S. Hu, N. P. Arbatsky, and X. Guo. 2015. Structural and genetic relationships of closely related O-antigens of Cronobacter spp. and Escherichia coli: C. sakazakii G2594 (serotype O4)/E. coli O103 and C. malonaticus G3864 (serotype O1)/E. coli O29. Carbohydr. Res. 404:124-131. https://doi.org/10.1016/j.carres.2014.11.014.

Son, L. C., D. N. Dai, T. D. Thang, D. D. Huyen, and I. A. Ogunwande. 2014. Analysis of the essential oils from five Vietnamese Litsea species (Lauraceae). Journal of Essential Oil Bearing Plants 17:960-971. https://doi.org/10.1080/0972060X.2014.935068.

Song, M., X. Wang, C. Mao, and W. Yao. 2018. The discovery of a potential antimicrobial agent: The novel compound natural medicinal plant fermentation extracts against Candida albicans. In The 5th Annual 2017 International Conference on Material Science and Environmental Engineering (MSEE2017), Huaqiao University, Xiamen, China. IOP Conference Series: Materials Science and Engineering, New Delhi, India.

Sun, J., T. Gao, Y. Li, Y. Liu, and B. Sun. 2015. Research on the antibacterial activity of aromatic aldehyde flavor compounds against four kinds of bacteria. Shipin Yu Fajiao Gongye 41:57-62. http:// qikan.cqvip.com/Qikan/Article/Detail?id=666353213.

Tyagi, P., M. Singh, H. Kumari, A. Kumari, and K. Mukhopadhyay. 2015. Bactericidal activity of curcumin I is associated with dam- 
aging of bacterial membrane. PLoS One 10:e0121313. https://doi .org/10.1371/journal.pone.0121313.

Wang, F., F. Wei, C. Song, B. Jiang, S. Tian, and J. Yi. 2017. Dodartia orientalis L. essential oil exerts antibacterial activity by mechanisms of disrupting cell structure and resisting biofilm. Ind. Crops Prod. 109:358-366. https://doi.org/10.1016/j.indcrop.2017.08.058.

Wang, H., and Y. Liu. 2010. Chemical composition and antibacterial activity of essential oils from different parts of Litsea cubeba. Chem. Biodivers. 7:229-235. https://doi.org/10.1002/cbdv.200800349.

WHO (World Health Organization). 2015. WHO Estimates of the Global Burden of Foodborne Disease Burden Epidemiology Reference Group 2007-2015. http://www.who.int/foodsafety/ publications/foodborne_disease/fergreport/en/.

Wu, Z., P. H. Raven, and D. Hong. 2008. Flora of China. Vol. 7. Missouri Botanical Garden Press, St. Louis, MO.

Xu, J. G., T. Liu, Q. P. Hu, and X. M. Cao. 2016. Chemical composition, antibacterial properties and mechanism of action of essential oil from clove buds against Staphylococcus aureus. Molecules 21:E1194. https://doi.org/10.3390/molecules21091194.

Yuan, L. Q. Hu, and J. Xu. 2015. Antibacterial mechanism of ethyl acetate extracts from naked oat against Bacillus subtilis. Aceh Int. J. Sci. Technol. (Banda Aceh) 4:20-25.

Yuan, W., and H. Yuk. 2018. Antimicrobial efficacy of Syzygium antisepticum plant extract against Staphylococcus aureus and methi- cillin-resistant $S$. aureus and its application potential with cooked chicken. Food Microbiol. 72:176-184. https://doi.org/10.1016/j.fm .2017.12.002.

Zengin, H., and A. H. Baysal. 2014. Antibacterial and antioxidant activity of essential oil terpenes against pathogenic and spoilageforming bacteria and cell structure-activity relationships evaluated by SEM microscopy. Molecules 19:17773-17798. https://doi.org/ 10.3390/molecules191117773.

Zhang, J., K. Ye, X. Zhang, D. Pan, Y. Sun, and J. Cao. 2017a. Antibacterial activity and mechanism of action of black pepper essential oil on meat-borne Escherichia coli. Front. Microbiol. 7. https:/ /doi.org/10.3389/fmicb.2016.02094.

Zhang, L., L. Zhang, Q. Hu, D. Hao, and J. Xu. 2017b. Chemical composition, antibacterial activity of Cyperus rotundus rhizomes essential oil against Staphylococcus aureus via membrane disruption and apoptosis pathway. Food Control 80:290-296. https://doi .org/10.1016/j.foodcont.2017.05.016.

Zhang, Y., Y. Wang, X. Zhu, P. Cao, S. Wei, and Y. Lu. 2017c. Antibacterial and antibiofilm activities of eugenol from essential oil of Syzygium aromaticum (L.) Merr. \& L. M. Perry (clove) leaf against periodontal pathogen Porphyromonas gingivalis. Microb. Pathog. 113:396-402. https://doi.org/10.1016/j.micpath.2017.10.054. 